Саркопения, или возрастассоцированное уменьшение количества скелетной мышечной ткани, является одной из наиболее распространенных и клинически значимых причин уменьшения эффективности функционирования скелетной мускулатуры у пожилых людей. Цель этой статьи - проанализировать: 1) текущие определения саркопении, 2) возможные причины ее возникновения и 3) клинические последствия, а также 4) возможность предупреждения и лечения данного заболевания. Саркопения была определена как заболевание, связанное с возрастом, характеризующееся непроизвольной потерей массы и силы скелетных мышц. Снижение мышечной силы и массы линейным образом было обнаружено начиная уже с 40-летнего обследуемых. Следует отметить, что к 80 годам жизни теряется до 50\% мышечной массы [6]. Учитывая, что мышечная ткань составляет до 60\% от общей массы тела, патологические изменения этой важной метаболически активной ткани могут иметь тяжелые последствия для пожилого человека, поскольку сила и снижение функциональной активности скелетной мускулатуры могут привести к полной утрате скелетными мышцами своих функции, инвалидности и слабости. Хотя консенсусный диагноз не был поставлен, саркопения в данный момент определяется как регистрацией потери мышечной массы, так и утратой мышечной функции и/или силы. Причина ее развития расценивается как многофакторная, с неврологическим уклоном, гормональными изменениями, активацией воспалительных путей, снижением физической активности, хроническими заболеваниями, жировой инфильтрацией и нерациональным питанием, которые, как было показано, являются факторами, способствующими развитию данного заболевания. Недавно полученные данные молекулярных исследований, направленных на изучение апоптоза клеток, снижения функциональной активности митохондрий и ангиотензиновой системы в скелетной мышце, выявили биологические механизмы, которые также могут приводить к возникновению саркопении.

Ключевые слова: Старение, саркопения, саркопенное ожирение, гериатрия.

\title{
AGE CHANGES OF MUSCULAR TISSUE. SARCOPENIA
}

Chalaya V.A., Seitmemetova S.A. Medical Academy named after S.I. Georgievsky, FGAOU VO "KFU named after V.I.Vernadsky, (295051, Russian Federation, Republic of Crimea, Simferopol, Lenin Boulevard, 5/7 Medical

Academy named after S.I. Georgievsky), e-mail: varvara.chala@gmail.com, seitmemetovas.02@mail.ru

Sarcopenia, or age-associated reduction in the amount of skeletal muscle tissue, is one of the most common and clinically significant reasons for the decrease in the efficiency of functioning of elderly people' skeletal muscles. The purpose of this article is to analyze: 1) the current definitions of sarcopenia, 2) the possible causes of its occurrence, 3 ) the clinical consequences, 4) the possibility of preventing and treating this disease. Sarcopenia was defined as a disease associated with age, characterized by involuntary loss of mass and strength of skeletal muscles. A decrease in muscle strength and mass in a linear fashion was discovered starting from the 40-year-old subject. It should be noted that by the age of 80 up to $50 \%$ of muscle mass is lost [6]. Considering that muscular tissue makes up to $60 \%$ of the total body mass, pathological changes of this important metabolically active tissue can have serious consequences for an elderly person, since the strength and decrease in the functional activity of skeletal muscles can lead to complete loss of function, disability and weakness by skeletal muscles.

Although a consensus diagnosis was not made, sarcopenia is currently determined by both the registration of loss of muscle mass and the loss of muscle function and / or strength. The cause of its development is regarded as multifactorial, with a neurological bias, hormonal changes, activation of inflammatory pathways, decreased physical activity, chronic diseases, fatty infiltration and poor nutrition, which have been shown to be factors contributing to the development of this disease. Recently obtained molecular studies aimed at studying cell apoptosis, reducing the functional activity of mitochondria and the angiotensin system in skeletal muscle, revealed biological mechanisms that can also lead to the appearance of sarcopenia.

Key words: Aging, sarcopenia, sarcopenic obesity, geriatrics. 


\section{Клиническое значение саркопении}

Определение саркопении является настолько емким, что включило в себя и ее клиническую значимость. Во-первых, ухудшение мышечного статуса напрямую связано с инвалидизацией, утратой способности к самообслуживанию и потерей физической независимости. Так, исследовательская группа ABC-Study (The Health, Aging, and Body Composition Study) оценивала влияние силы мышц и состава тела на ограничение подвижности. В результате прогностическим фактором этого ограничения явилась неспособность пройти 400 м или преодолеть лестничный пролет в 10 ступеней. Мужчины и женщины с наиболее низкими значениями площади поперечного сечения бедра на 30-40\% чаще были неспособны выполнять необходимый уровень повседневной активности. При использовании специальных опросников показано, что сила и выносливость скелетных мышц, а также возможность совершать быстрые повороты тела определяют 96\% ограничений повседневной активности. Сила мышц бедра и площадь их поперечного сечения имеют корреляционную связь с частотой переломов шейки бедренной кости. При этом уменьшение величины максимального усилия разгибателей колена увеличивало риск перелома на $50-60 \%$ независимо от минеральной плотности кости.

Табл. 1 Изображений компьютерной томографии здорового молодого человека и пациента с клиническими проявлениями саркопении:
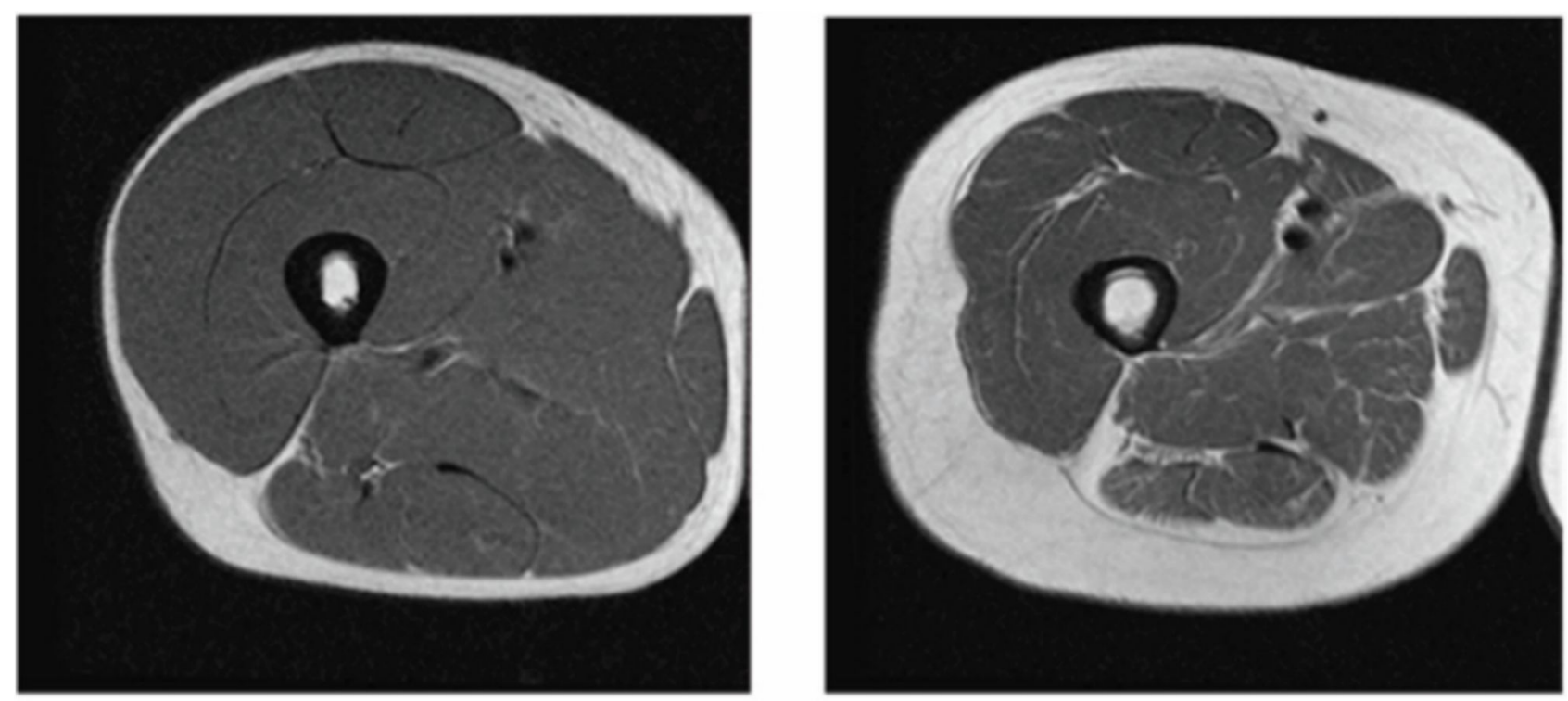

Причины возникновения саркопении

В зависимости от причины выделяют первичную (возраст-ассоцированную) и вторичную саркопению. Первичная форма развивается с возрастом при отсутствии влияния различных вторичных факторов на скелетную мышечную ткань. Вторичная саркопения может быть обусловлена низкой физической активностью, нарушением питания и хроническими заболеваниями, в том числе воспалительными. Недавние исследования показали высокую 
распространенность саркопении среди пациентов с онкологическими заболеваниями (15-50 \%), печеночной недостаточностью (30-45 \%) и больных в критическом состоянии, находящихся в отделении реанимации и интенсивной терапии (60-70 \%).

Также предлагается выделять тяжесть изменения состояния мышечной ткани, которая отображается в стадийности развития саркопении. Научная группа EWGSOP выделила три стадии развития саркопении:

I - пресаркопения, характеризуется снижением мышечной массы без снижения ее силы и функции;

II - саркопения, характеризуется снижением скелетной мышечной массы, ее силы или функции;

III - тяжелая форма саркопении, характеризуется снижением всех трех параметров (мышечной массы, ее силы и функции).

Следует отметить, что в результате проведенных исследований были получены приведенные ниже данные:

в возрастной группе 55 - 65 лет в 77 - 90\% случаев саркопенных изменений не было зарегистрировано, и лишь у 10 - 23\% пациентов были выявлены пресаркопенические изменения. Возрастные изменения на уровне саркопении или выраженной саркопении не были зарегистрировангы.

С увеличением возраста от 66 до 80 лет полное отсутвие саркопении в процентном соотношении со стадиями саркопении уменьшается. Появляется и увеличивается количество пациентов с саркопенией или выраженной саркопенией (Табл. 2).

Причина саркопении, как правило определяется как многофакторная, с экологическими факторами, триггерами болезни, активацией воспалительных путей, нарушениями митохондрий, потерей нервно-мышечных синапсов, уменьшением числа клеток-сателлитов и гормональными изменениями, которые, как считается, способствуют: снижению физической активности и количества потребляемой пищи, повышению воспалений, снижению количества мотонейронов, гормональным изменениям, возрастным молекулярным изменениям.

В экологических причинах обычно выделяют снижение физической активности и потребления пищи. Пожилые люди менее активны, отчасти из-за повышенной хронической болезни, которая приводит к боли и усталости. Кроме того, снижение потребления белка и калорий, а также избыточное питание, которое приводит к саркопенному ожирению и ускоренной потере мышечной массы и функции, являются важными факторами развития саркопении у пожилых людей. В совокупности эти воздействия окружающей среды накладываются на многофакторное, связанное с возрастными биологическими изменениями, которое приводят к снижению массы и силы скелетных мышц, как описано ниже. 
Табл. 2 Статистические данные встречаемости форм саркопении.

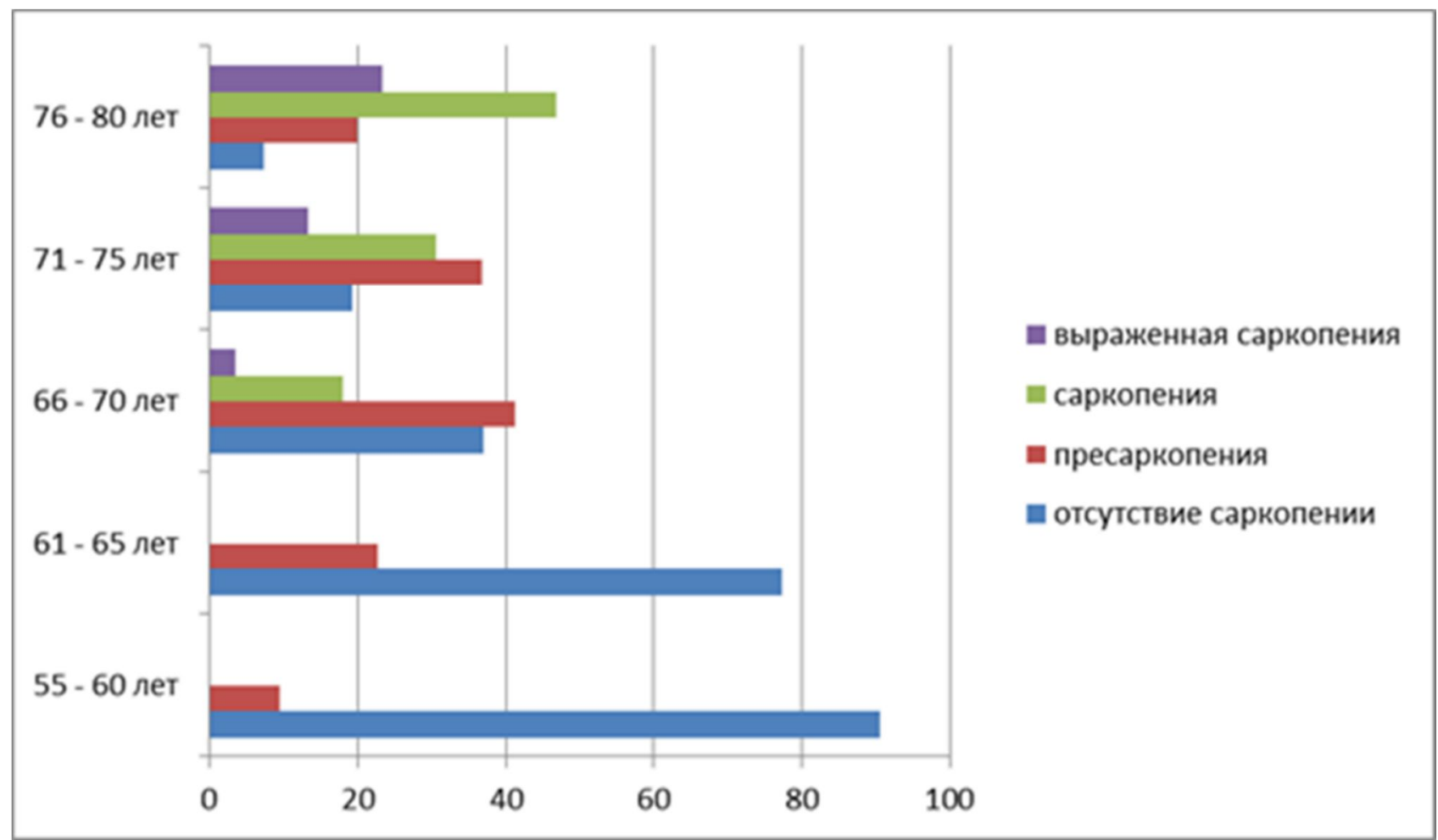

Считается, что снижение количества нервно-мышечных синапсов с уменьшением количества быстрых (миелиновых) мышечных волокон или волокон 2-го типа играет важную роль в снижении количества мышечной массы. Недавние исследования у пожилых самок мышей продемонстрировали поразительное увеличение доли полностью денервированных нервномышечных синапсов, особенно в быстрых мышечных волокнах, таких как extensor digitorum longus [4]. Интересно, что число мотонейронов в спинном мозге, которые иннервируют эту область, не уменьшается, что указывает на то, что может происходить уменьшение количества аксонов, а не изменение нервного тела. Из-за важности этой потери для развития саркопении у людей, новое диагностическое скрининговое измерение С-концевого фрагмента агрина, который был идентифицирован как маркер снижения нервно-мышечного соединения у пожилых мужчин, крайне важно [2].

Снижение количества гормонов, которые важны для поддержания мышечной массы, включая инсулиноподобный фактор роста-1, дегидроэпиандростерон-сульфат, тестостерон и эстроген, также, вероятно, способствует саркопении $[5,8]$. Эти пути также представляют собой важные потенциальные возможности для лечебного вмешательства в саркопению.

Активация воспалительного пути, вероятно, из-за различных причин заболевания и старения, как известно, является важным фактором саркопении. Исследование уровней сывороточного воспалительного цитокина интерлейкина-6 и его связи с мышечной силой у пожилых женщин продемонстрировало более резкое снижение способности ходить, более высокий риск 
развития физической инвалидности, частично объясняемый параллельным снижением прочности скелетных мышц. Это может быть отчасти связано с важным влиянием хронического воспалительного цитокинового воздействия на клетки-сателлиты в мышечных волокнах. Источников воспаления у пожилых людей может быть несколько. Конечно, хронические заболевания являются одними из наиболее распространенных триггеров активации воспалительного пути. Многие воспалительные ревматологические состояния, такие как системная красная волчанка и ревматоидный артрит, связаны с мышечной потерей, которая, как считается, связана с хронической активацией воспалительных путей, что в свою очередь отрицательно влияет на регенерацию мышц [4, 9]. Многие другие хронические состояния, включая почечную недостаточность и застойную сердечную недостаточность, вероятно, ускоряют развитие саркопении путем повышения количества воспалительных медиаторов.

Наконец, все более очевидной становится утрата способности к обновлению и регенерации скелетных мышц. Скелетные мышечные стволовые клетки (СК), имеющие решающее значение для регенерации скелетных мышц у пожилых и молодых людей, по-видимому, у пожилых людей, мигрируют гораздо медленнее, чем СК в молодом организме, и их подвижность затрудняется, возможно, частично из-за низких уровней интегрина [1].

Новые молекулярные данные, связанные с саркопенией

В основе более выраженных физиологических причин лежит множество связанных с возрастом и с болезнями биологических изменений, которые повышают уязвимость пожилых людей. Некоторые важные новые исследования помогли пролить свет на связанные со старением молекулярные триггеры для саркопении. Так, было доказано, что митохондриальная функция и биогенез митохондрий изменяются в скелетных мышцах пожилых людей, что, в свою очередь, способствует изменению массы и функции скелетных мышц [4]. Недавно были выявлены связанные с возрастом изменения в системе ангиотензина, которые сыграли решающую роль в заживлении скелетных мышц при травматическом повреждении и при их атрофии [10]. Важно отметить, что при этом же исследовании было обнаружено, что блокирующий агент лозартан 1-го рецептора ангиотензина 1-го типа помогает ускорить регенерацию скелетных мышц и предотвратить их атрофию у пожилых особей мышей, вероятно, в ответ на понижающую регуляцию путей TGF- $\beta$. Было также продемонстрировано, что лозартан увеличивает количество рецепторов 2-го типа ангиотензина в митохондриях более пожилых мышей, что, в свою очередь, объясняет некоторые улучшения при скелетно-мышечных заболеваниях, наблюдаемые у более пожилых мышей, получавших лозартан [4, 7]. Апоптоз или запрограммированная гибель клеток также могут играть важную роль в развитии саркопении. 
Касательно опытов на человеке, исследования белков, связанных с апоптозом, показали их повышенное содержание у пожилых людей с меньшим объемом мышц бедра и более медленной скоростью ходьбы, что указывает на то, что апоптоз может способствовать уменьшению мышечной массы. Недавно был обнаружен фактор, вызывающий апоптоз, находящийся в межмембранном пространстве митохондрий, для защиты предшественников скелетных мышц или спутниковых клеток от апоптоза до тех пор, пока он не будет высвобожден в цитоплазму клеток.

Лечебные вмешательства при саркопении

Несмотря на значительный прогресс в понимании многофакторных причин саркопении, большинство лечебных вмешательств были направлены на исключение экологических причин возникновения данной патологии, а именно на увеличение физической активности и обеспечение адекватного питания. Результаты исследований клинического вмешательства даже у самых старых и слабых жителей дома престарелых продемонстрировали значительное функциональное улучшение за счет сочетания отрегулированного питания и резистентных физических упражнений, которое характеризуется значительным увеличением синтеза мышечного белка, положительным влиянием на дисфункцию сателлитных клеток, снижение нервно-мышечных синапсов и биогенез митохондрий $[3,8]$. Будущие фармацевтические вмешательства при саркопении также, вероятно, будут нацелены на очень специфические молекулярные пути, такие как ангиотензиновая система, апоптоз и митохондриальная функция.

Заключение

Саркопения остается важной клинической проблемой, которая поражает миллионы пожилых людей. Несмотря на высокую распространенность данного заболевания, его четкого определения на данный момент не существует. Причины развития саркопении включают снижение гормонов и количество нервно-мышечных синапсов, повышенное воспаление, снижение активности и недостаточное питание. Новые молекулярные открытия, которые могут повлиять на методы лечения саркопении, включают изменения в митохондриальной биологии, ангиотензиновой системе и апоптозе. Продолжаются мероприятия по борьбе с саркопенией, причем основное внимание уделяется физическим упражнениям и коррекции питания пациентов. Отчасти из-за отсутствия консенсусного определения саркопении разработка фармацевтических препаратов для лечения данной патологии частично замедлилась. В связи с широкой распространенностью рассмотренного заболевания необходимы эпидемиологические исследования по изучению факторов риска саркопении у лиц старших возрастных групп, разработка методов и средств диагностики, профилактики и лечения нарушений функционального состояния мышечной системы. 
Ссылки на источники:

1. Collins-Hooper $\mathrm{H} /$ Age-related changes in speed and mechanism of adult skeletal muscle stem cell migration / Woolley TE, Dyson L, Patel A, Potter P, Baker RE, Gaffney EA, Maini PK, Dash PR, Patel K // doi: 10.1002/stem.1088

2. Drey M / C-terminal Agrin Fragment as a potential marker for sarcopenia caused by degeneration of the neuromuscular junction / Sieber CC, Bauer JM, Uter W, Dahinden P, Fariello RG, Vrijbloed JW; FiAT intervention group // doi: 10.1016/j.exger.2012.05.021

3. Fiatarone M.A / Exercise training and nutritional supplementation for physical frailty in very elderly people / Evelyn F. O'Neill, Nancy Doyle Ryan, Karen M. Clements, Guido R. Solares, Miriam E. Nelson, Susan B. Roberts, Joseph J. Kehayias, Lewis A. Lipsitz, and William J. Evans // doi: 10.1056/NEJM199406233302501

4. Joseph AM / The impact of aging on mitochondrial function and biogenesis pathways in skeletal muscle of sedentary high- and low-functioning elderly individuals / Adhihetty PJ, Buford TW, Wohlgemuth SE, Lees HA, Nguyen LM, Aranda JM, Sandesara BD, Pahor M, Manini TM, Marzetti E, Leeuwenburgh C // doi: 10.1111/j.1474-9726.2012.00844.x

5. McIntire KL / The endocrine system and sarcopenia: potential therapeutic benefits / Hoffman AR. Curr Aging Sci. 2011 Dec;4(3):298-305. Review // PMID: 21529322

6. Metter EJ / Age-associated loss of power and strength in the upper extremities in women and men / Conwit R, Tobin J, Fozard JL // J Gerontol A Biol Sci Med Sci. 1997/ PMID: 9310077

7. Peter $\mathrm{M} /$ Identification and characterization of a functional mitochondrial angiotensin system / Abadir, D. Brian Foster, Michael Crow, Carol A. Cooke, Jasma J. Rucker, Alka Jain, Barbara J. Smith, Tyesha N. Burks, Ronald D. Cohn, Neal S. Fedarko, Robert M. Carey, Brian O’Rourke, and Jeremy D. Walston // doi: 10.1073/pnas.1101507108

8. Sakuma K / Sarcopenia and age-related endocrine function / Yamaguchi A. Int J Endocrinol // doi: $10.1155 / 2012 / 127362$

9. Santos MJ / Body composition phenotypes in systemic lupus erythematosus and rheumatoid arthritis: a comparative study of Caucasian female patients / Vinagre F, Canas da Silva J, Gil V, Fonseca JE. Clin Exp Rheumatol. 2011 May-Jun;29(3):470-6. Epub 2011 Jun 29 // PMID: 21640047

10. Snijders T/ The impact of sarcopenia and exercise training on skeletal muscle satellite cells / Verdijk LB, van Loon LJ // doi: 10.1016/j.arr.2009.05.003 